ORIGINAL ARTICLE

\title{
National review of urology outpatient practice in the UK
}

\author{
P E Gilmore, D C Shackley, N W Clarke, C D Befts, K J O'Flynn
}

Postgrad Med J 2005;81:55-57. doi: 10.1136/pgmj.2004.020693

See end of article for authors' affiliations

......................

Correspondence to: Mr Paul Gilmore,

Department of Urology,

Hope Hospital, Stott Lane

Salford, Greater

Manchester M6 8HD, UK;

paul.gilmore1@

tiscali.co.uk

Submitted

16 February 2004

Accepted

27 February 2004

\begin{abstract}
Objective: To audit the current UK outpatient workload and compare this to the national standards as set out by the British Association of Urological Surgeons (BAUS) in A Quality Urological Service for Patients in the New Millennium published in October 2000.

Participants: 520 UK (NHS) and 21 Republic of Ireland (non-NHS) consultant urologists registered with BAUS in 2000.

Main outcome measures: Extent to which consultant urologists are able to comply with guidelines set out by their specialist association, the BAUS and by the Royal College of Surgeons of England.

Results: The questionnaire return rate was 61\% (318/520; regional range 42\%-75\%). The median "routine" clinics/week was two (1-5) with a mean of 13 (1-40) new and 26 (7-80) follow ups. Fiffeen percent (49/318) of consultants worked alone in clinic; of the remainder assistance included specialist registrar $67 \%(212 / 318)$, staff grade/associate specialist 32\% (102/318), senior house officer $53 \%(172 / 318)$, and pre-registration house officer $2 \%(7 / 318)$. Only $21 \%(66 / 318$; regional range $0 \%-46 \%$ ) of responding consultants followed the BAUS recommendations for outpatient workload/ manpower.

Conclusions: A minority of consultants are able to adhere to the outpatient workload guidelines as set out by BAUS council in 2000. In addition, there appears to be significant variations within and between training regions. Development of this project into a regional audit tool may allow intraregional guideline formation governing hospital outpatient workload.
\end{abstract}

l October 2000, the Council of the British Association of Urological Surgeons (BAUS) in conjunction with the Royal College of Surgeons of England produced the document $A$ Quality Urological Service for Patients in the New Millennium which set out to assist health authorities, trust chief executives, clinical directors, and consultant urologists in planning urological services for their community. ${ }^{1}$ In part, this set down guidelines on outpatient workload, manpower, and standards of care and its conclusions were intended to apply to all NHS consultant urologists. The outpatient guidelines were produced after a consultation period, were felt to comply with the government's initiatives on improvements in the quality of healthcare, and were broadly consistent with advice issued from other surgical specialty associations and the Royal College of Surgeons. ${ }^{1-3}$ After a review of the literature, we can find no evidence of a national urological outpatient audit either before or after the publishing of the BAUS guidelines document and there would appear, therefore, to be no benchmarks for future auditing of outpatient workload intensity. This paper seeks to address this deficiency. We conducted a national questionnaire based audit to assess at regional and national levels the current clinic based workload and, in particular, to ascertain whether current outpatient practice reflects national guidelines.

\section{METHODS}

A questionnaire was designed to assess individual consultant's outpatient workload and service provision. In view of the large numbers of questionnaires being sent to contemporary consultants, every effort was made to keep the returnable form simple with four questions asked on a single side of paper. The questionnaire asked about the number of new and follow up patients seen in each outpatient clinic, the numbers of such clinics per week, the level of service provision available, and finally a tick box for allocation of the data into geographical regions. In order to try to standardise the returns, the data were requested for "routine" urology clinics rather than specific outpatient sessions (for example, flexible cystoscopy clinic, etc, were not included). No attempt was made to separate the outpatient data of consultants who have a large subspecialist interest from "core" urologists since this audit was designed to assess each and every urology consultant's clinic based workload.

The questionnaire was posted in September 2002 to all UK consultant urologists registered with BAUS in the handbook of 2000 (520). The respondent's identity was kept anonymous. Data were entered onto a Microsoft Excel database with analysis performed on all evaluable completed forms received by the 31 December 2002 . Where data included a variance in service provision, the number of doctors at each grade was averaged out to make a valid picture of medical staffing per clinic. Where consultants returned more than one questionnaire (for example, two base hospitals), the data were averaged into one entry since this audit was designed to assess individual consultant rather than hospital based practice.

The BAUS council document A Quality Urological Service for Patients in the New Millennium issued guidelines on the maximum numbers of patients that should be seen in clinic given the level of service provision. Table 1 summarises these figures. Calculations were made for each urologist with guideline compliance achieved if the total number of patients seen in each clinic was equivalent or less than the sum of the maximum numbers of patients allowed for each member of staff. From this analysis, it was possible to calculate the proportion of consultants who were able to meet the BAUS guidelines.

All the above data were analysed together to give an overall picture, and also in regional cohorts to illustrate any geographical variations.

\section{RESULTS}

Of the 520 UK consultant urologists, 322 returned the questionnaire. Four of these were discarded because of 


\begin{tabular}{l}
$\begin{array}{l}\text { Table } 1 \text { Suggested workload for each grade } \\
\text { of doctor working in a urological clinic* }\end{array}$ \\
\hline $\begin{array}{l}\text { Suggested maximum } \\
\text { numbers of patients } \\
\text { seen per clinic }\end{array}$ \\
Grade of surgeon \\
\hline $\begin{array}{l}\text { Consultant } \\
\text { SpR (year } 3 \text { or above)/staff }\end{array}$ \\
grade/associate specialist \\
SpR (years 1+2) \\
SHO \\
$\begin{array}{l}\text { SHO, senior house officer; SpR, specialist registrar. } \\
\text { *These data are based on doctors seeing an equal mix of }\end{array}$ \\
new and follow up patients in a session. The consultation \\
times accepted as standard are 20 minutes for new and \\
10 minutes for follow up patients. These figures represent the \\
maximum numbers of patients which should be seen in \\
outpatient clinics taking into account individual case \\
complexity and adjusting consultation length for the ratio of \\
new: follow up patients, which depends on the specific \\
dynamics of the clinic as well as local pressures.
\end{tabular}

insufficient or incomplete details leaving 318 (61\%) evaluable forms (regional range $42 \%-75 \%$ ) (fig 1 ). The median number of urology clinics undertaken per week was two (range 1-5), which consisted of a mean of 13 (range 1-40) new patients and 26 (range 7-80) follow up patients per clinic. Consultants worked alone in outpatient clinics in $15 \%$ of cases (49/318). Of the remainder, additional service provision within clinics included specialist registrars in $67 \%$ of cases (212/318), associate specialist and staff grade doctors 32\% (102/318), senior house officers 53\% (172/318), and pre-registration house officers $2 \%$ (7/318). Twenty one percent (68/322) of responding UK based urologists were able to adhere to the guidelines, with a large variation between differing training regions (ranges illustrated by Northern Ireland $0 \%$ and East Scotland $46 \%$ ) (fig 2).

Data from the BAUS registered Republic of Ireland consultants were also collected for comparison. Full analysis in conjunction with the UK based consultants was felt inappropriate because Irish consultants work outside the NHS and the BAUS council document on workload is specific only to the UK consultant cohort. Of the 21 consultants, eight returned evaluable forms (38\%) and two of these $(25 \%)$ had outpatient practices that would fall within the BAUS guidelines.

\section{DISCUSSION}

There are mounting pressures on doctors in the outpatient clinic. These include centrally driven targets for outpatient waiting times (for example, maximum wait of three months by 2005 and urgent cancer referrals being seen by a hospital specialist within two weeks ${ }^{4}$ ), the Patient's Charter, ${ }^{5}$ and a continuing increase in new patient referrals (across all specialties: nine million in calendar year $1991,{ }^{6} 12.5$ million in financial year $\left.2000-1^{7}\right){ }^{8}$ In addition, the historical precedents for numbers of patients seen in clinic are inappropriate for contemporary practice. This is mainly due to the growing expectations of patients who are better informed about their condition and its treatment who require more detailed counselling and explanation. The guidelines published by BAUS in October 2000 after a period of consultation were intended to advise politicians, managers, and urologists in formulating an appropriate outpatient workload. They were designed to strike a balance between managerial pressures on the one hand and the requirement to produce a high quality service on the other. ${ }^{9}$ This study illustrates that only a minority $(21 \%)$ of urological consultants working within the UK in 2002 are able to conform to these outpatient guidelines.

There is a continuing shift from inpatient to outpatient care in the UK and yet outpatient clinics receive much less attention than other elements of hospital work, a feature that is borne out by the relative paucity of published studies. There is some evidence outside of individual hospital auditing to show that clinics are oversubscribed: a study by the London based Health Services Research Unit in 2000 concluded that most clinics were "operated in the face of pervasive pressures on time, which created a service that was seen as meeting no-one's needs adequately" ${ }^{\prime \prime} .^{10}$ In studies of general surgical outpatient clinics, it was found that $27 \%$ of patients thought the time spent with their doctor was too short and that $78 \%$ of clinics over-ran their schedule time. ${ }^{11-13}$ A recent audit of 10 consecutive routine urology outpatient clinics showed that the mean time spent with the patient in 2001 was 4.8 minutes, which contrasts sharply with the figure of 7.6 minutes obtained during their departments'

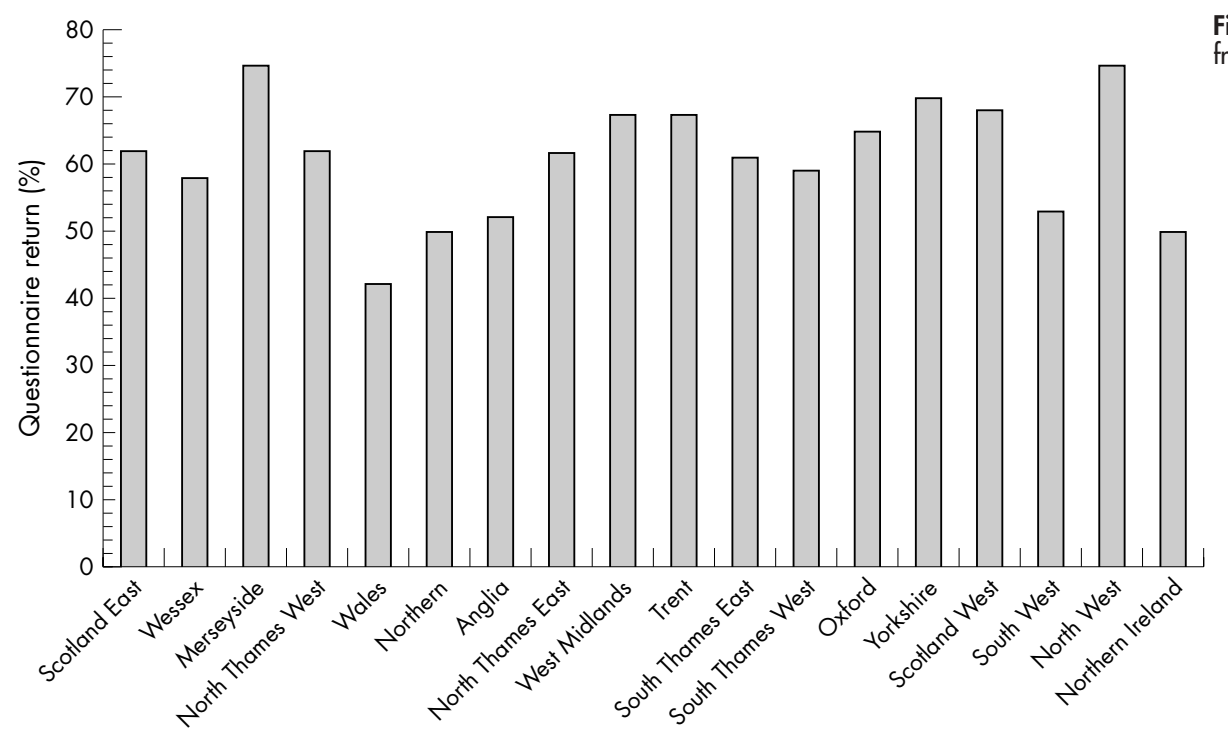

Figure 1 Postal questionnaire return from UK consultant urologists.

Region 


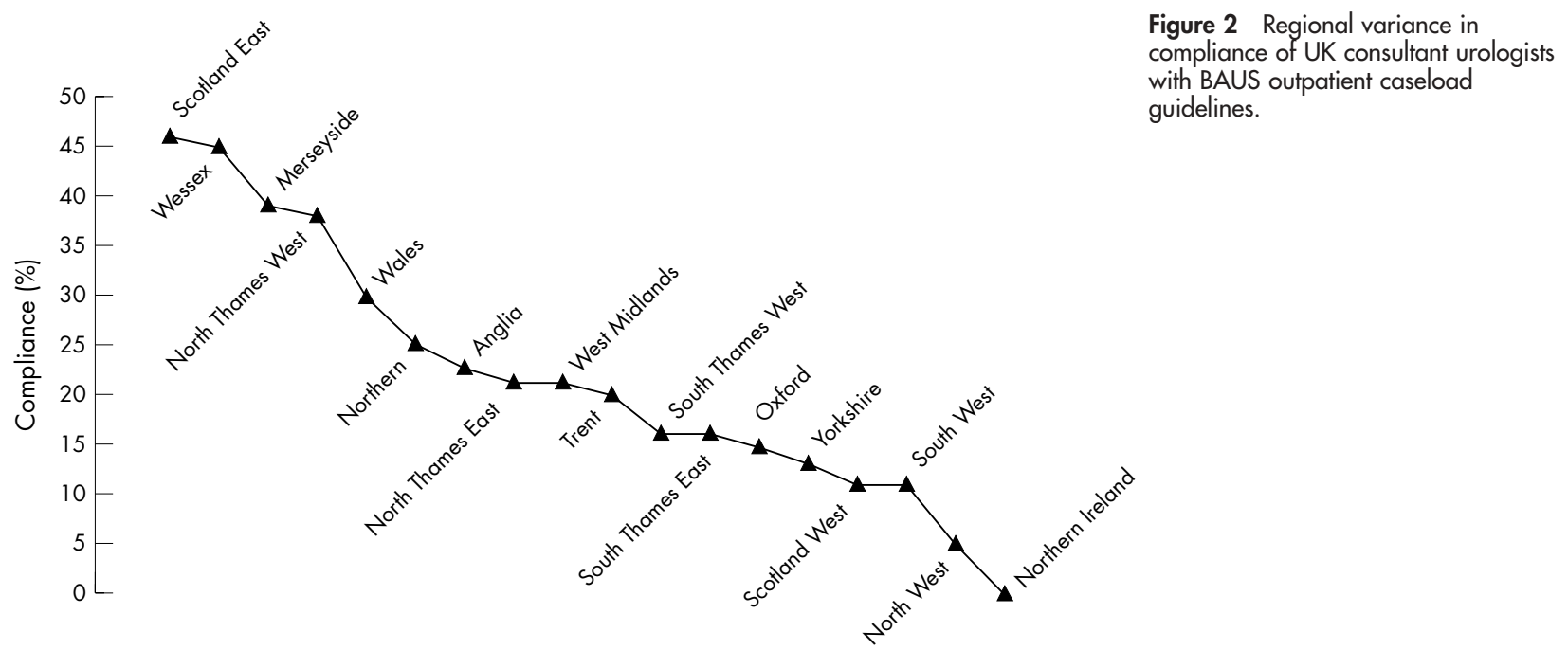

Training region

previous audit in 1988. ${ }^{14}{ }^{15}$ These data do not sit easily with evidence that shows that the length of time spent with the surgeon is of paramount importance to patients' overall satisfaction of the outpatient clinic process. ${ }^{16-19}$ While there is little doubt from published research in both community and hospital based clinics that longer consultation times lead to improved patient satisfaction, there is a shortage of published data looking at other outcome parameters. It is therefore, not possible to make any firm conclusions regarding consultation length and its subsequent impact on investigation, intervention, prescribing practice, or indeed patient outcome.

The results are deliberately presented in geographical cohorts to allow regional groupings to perform their own future audits on compliance with the BAUS guidelines. It is possible that such data may support an application for future additional consultant posts. It is interesting that the results here show a marked variation between different regions. Even in adjacent training areas there are large differences in outpatient workload. It is unlikely that differing levels of regional funding, local changes in ratios of junior medical staff to consultants, or degrees of subspecialisation account for all the discrepancy seen. Because there are no previous national audit figures for urological outpatient workload, it is difficult to be sure whether these regional variations are historical or due to some consultants being more proactive than others in trying to meet the BAUS guidelines.

The main message of our study is that very few consultants are meeting their specialist guidelines of suggested levels of clinic based activity. Excess workload in clinic clearly impacts on the quality of healthcare delivered and consultants should be aware of workforce guidelines and seek to achieve them. Intraregional auditing may be beneficial in achieving this goal. Increased awareness of the benefits of national standards is required to allow for uniform practice among hospital services across the NHS.

\section{ACKNOWLEDGEMENTS}

We would like to thank all the consultant urologists registered with the British Association of Urological Surgeons for both their time to complete the questionnaires and for their encouragement in our pursuing this project.

\section{Authors' affiliations}

P E Gilmore, C D Betts, K J O'Flynn, Department of Urology, Hope Hospital, Salford, Greater Manchester, UK

D C Shackley, N W Clarke, Department of Urology, Hope Hospital, Salford and Department of Surgery, Christie Hospital, Manchester,

Greater Manchester, UK

\section{REFERENCES}

1 Council of the British Association of Urological Surgeons. A quality urological service for patients in the new millennium. BAUS, October 2000.

2 Royal College of Surgeons of England. General surgical workload and the provider/purchaser contract. Notes for guidance. London: RCS, 1990.

3 Royal College of Surgeons of England. The surgical workforce in the new NHS. London: RCS, November, 2001.

4 Department of Health. The NHS plan. London: Department of Health, July 2000.

5 Department of Health. The patient's charter. London: HMSO, 1991.

6 Armstrong D, Nicoll M. Consultants' workload in outpatient clinics. BMJ 1995;310:581-2.

7 Department of Health website. Data on first outpatient clinic attendances 2000-1. Available at: www.doh.gov.uk/hospital activity/statistics.

8 Wagstaff MH, Rigby ML, Redington AN. Increasing workload and changing referral patterns in paediatric cardiology outreach clinics: implications for consultant staffing. Heart 1998;79:223-4.

9 Department of Health. A first class service-quality in the new NHS. London: Department of Health, 1998.

10 McKee M, Waghorn A. Why is it so difficult to organise an outpatient clinic? Health Serv Res Policy 2000;5:140-7.

11 Waghorn A, McKee M. Understanding patients' views of a surgical outpatient clinic. J Eval Clin Pract 2000;6:273-9.

12 Waghorn A, Mc Kee M. Surgical outpatient clinics: are we allowing enough time? Int J Qual Health Care 1999;11:215-9.

13 Benson RJ, Burnet M, Williams MV, et al. An audit of clinic consultation times in a cancer centre: implications for national manpower planning. Clin Oncol $2001 ; 13: 138-43$

14 Patel HRH, Luxman CN, Bailey TS, et al. Outpatient clinic: where is the delay? $J$ R Soc Med 2002;95:604-5.

15 Duncan K, Beale K, Parry J, et al. Outpatients: can we save time and reduce waiting lists. BMJ 1988;296:1247-8.

16 Chung KC, Hamill JB, Kim HM, et al. Predictors of patient satisfaction in an outpatient plastic surgery clinic. Ann Plast Surg 1999;42:56-60.

17 Cartwright A, Windsor J. Outpatients and their doctors. London: Department of Health Institute for Social Studies in Medical Care, 1992.

18 Morrell DC, Evans ME, Morris RW, et al. The "five minute" consultation: effect of time constraint on clinical content and patient satisfaction. BMJ 1986;292:870-3.

19 De Brun C, Howell F, Bedford D, et al. Outpatient experiences in acute hospitals. Irish J Med Sci 2002;171:89-93. 